\title{
Research Progress of PV Mounting System for Solar Power Station
}

\author{
NI Hongjun \\ School of Mechanical Engineering \\ Nantong University \\ Nantong, Jiangsu, China \\ E-mail: ni.hj@ntu.edu.cn \\ LU Wenfan \\ School of Mechanical Engineering \\ Nantong University \\ Nantong, Jiangsu, China \\ E-mail:1508699921@qq.com \\ Wang Xingxing* \\ School of Mechanical Engineering \\ Nantong University \\ E-mail: wangxx@ntu.edu.cn
}

\author{
Lu Haoyang \\ School of Mechanical Engineering \\ Nantong University \\ Nantong, Jiangsu, China \\ E-mail: familyylxq@163.com \\ Zhang Yongpei \\ Engineering R \& D Center \\ Jiangsu Lead Aluminum Co., Ltd \\ Nantong, Jiangsu, China \\ Zhang Minqi \\ Engineering R \& D Center \\ Jiangsu Lead Aluminum Co., Ltd. \\ Nantong, Jiangsu, China
}

\begin{abstract}
Reviewed the summary and classification of PV mounting system for solar power station. Analyzed the advantages and disadvantages of the optimum tilt angle of fixed, the horizontal single-axis tracking type, the diagonal single axis tracking type and the dual axis tracking type mounting system for solar power station, compared the performance of the different installation methods and materials of the PV mounting system from the bearing capacity, corrosion resistance, beautiful degree stability, construction speed, connection strength and other aspects. Introduced in detail of PV mounting system for solar power station design principles and load cases, compared and analyzed comprehensive performance of the four forms of PV mounting systems from the covering area, solar radiation gain, the capacity gain and other aspects. Summarized the problems and proposed solutions of existing PV mounting system, and proposed the development direction of PV mounting system for solar power station.
\end{abstract}

Keywords-Solar; PV systems; Mounting; Tracking system; solar power station

\section{INTRODUCTION}

Since twenty-first Century, the human society is facing a series of challenge, the energy crisis is one of the most concern problem in today's world ${ }^{[1-2]}$. The shortage of energy, the deterioration of the environment to promote human development of new energy, hydro energy, wind energy, ocean energy, solar energy, geothermal energy, these 5 kinds of new energy sources, solar energy is the most development potential. It is a kind of inexhaustible, clean, safe and renewable energy ${ }^{[3-4]}$. The global photovoltaic market demand breakthrough 40GW in 2014, industry demand growth remained at the level of
20\% 30\%, China's installed capacity of photovoltaic grid connected at about $10.5 \mathrm{GW}$, the cumulative installed PV capacity is $26.52 \mathrm{GW}$, which distributed photovoltaic power station does not exceed 5GW, large ground station is mainly part of the PV market in China. In the cost of the solar photovoltaic power generation system, Solar support costs accounting for approximately $11 \%$,that is second only to $55 \%$ of the sun battery costs, and to $13 \%$ of the variable-frequency drive. At present the solar mounting system can not meet the requirements of the new development. In fact, a professional photovoltaic bracket system should not only consider the wind, snow, earthquake and the factors influencing the stability, but also consider the various photovoltaic module compatibility, conservation and the use of material, can realize large-scale production, or even consider the transportation and installation and maintenance of the safety and convenience ${ }^{[5]}$. Photovoltaic bracket system compared to the foreign mature markets, the current domestic photovoltaic bracket system also has many disparities $^{\left[{ }^{[6]}\right.}$.

\section{A. The classification of PV mounting}

system for solar power station

The Solar photovoltaic bracket is designed to put a special support, installation, fixed solar panel solar energy in PV system. According to PV mounting system for solar power station operation mode can be divided into: the optimum tilt angle of fixed, the horizontal single-axis tracking type, diagonal single axis tracking type and dual axis tracking type ${ }^{\text {[7] }}$. 
1) The optimum tilt angle of fixed

The fixed support usually have a certain angle, the installation angle of the optimal choice depends on many factors, such as geographical location, distribution of annual solar radiation, direct radiation and scattering of radiation ratio and specific site conditions etc. Best installation angle can use professional design software system to determine the optimum design, it should be the angle at the system generating annual maximum time. The domestic and international professional software include Meteonorm, Photovoltaic treasure, PVSystem.

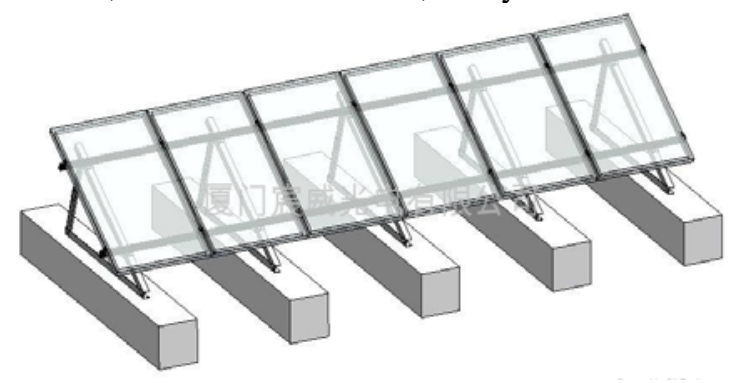

Figure 1. The optimum tilt angle of fixed

2) The horizontal single axis tracking

The level of a single axis tracking support, through its rotation in the east-west direction, in order to ensure the normal direction of each moment the sun light and the solar cell panel to a minimum, so as to gain power in large quantity.

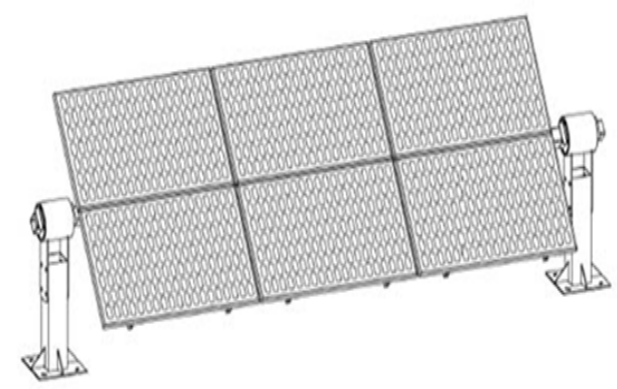

Figure 2. The horizontal single axis tracking

3) The diagonal single axis tracking type

Also known as the tilt angle of a single axis tracking support dimension. Tilted single axis tracking support, is based on fixed solar cell panel angle, rotate about the axis sun tracking range of the tilt angle, in order to receive more solar radiation amount. Li Shimin designed the "solar photovoltaic power generation component of the oblique / horizontal single axis tracking device", the device can improve the photovoltaic array experiments show that generating capacity more than $25-30 \%{ }^{[8]}$.

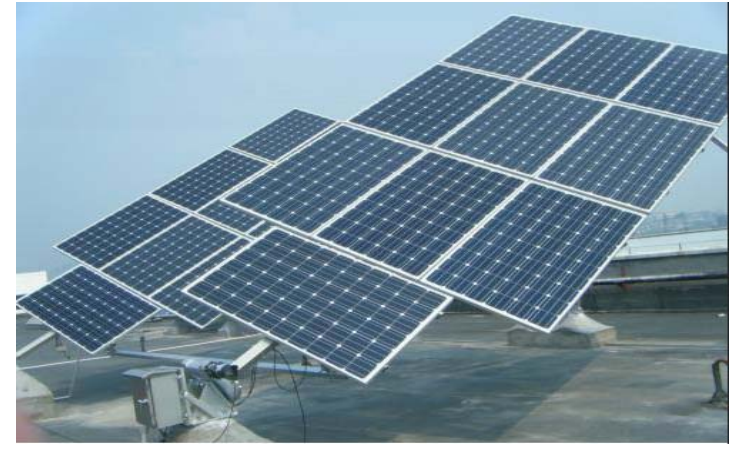

Figure 3. The diagonal single axis tracking

4) The dual axis tracking

Two axis tracking bracket can motion along the two rotating shaft, can also track the sun's azimuth and elevation angle, can be theoretically by the real-time tracking of the sun's rays, in order to ensure that every moment in the sun light and solar cell panel is vertical, in order to obtain the maximum amount of electricity. Gao Dianjun invented the "solar power generation unit and a solar battery board support and elevation tracking unit", after the final test in the experimental process, the generation rate of fixed bracket contrast at the same level, can improve the generation rate of $18 \%{ }^{[9]}$.

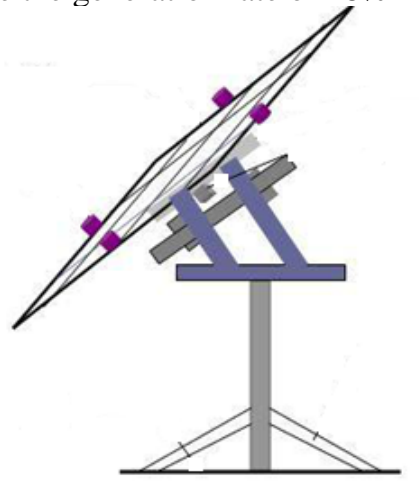

Figure 4. The dual axis tracking

According to the support system of photovoltaic materials can be divided into: non metallic stent, aluminum alloy frame, steel frame.

TABLE I. DIFFERENT MATERIAL PV MOUNTING SYSTEM PERFORMANCE COMPARISON

\begin{tabular}{|l|l|l|l|l|}
\hline $\begin{array}{l}\text { Support } \\
\text { classifica- } \\
\text { tion }\end{array}$ & stability & $\begin{array}{l}\text { Corrosi } \\
\text {-on } \\
\text { resistan } \\
\text {-ce }\end{array}$ & $\begin{array}{l}\text { beautiful } \\
\text { degree }\end{array}$ & $\begin{array}{l}\text { Bearing } \\
\text { capacity }\end{array}$ \\
\hline $\begin{array}{l}\text { non } \\
\text { metallic } \\
\text { stent }\end{array}$ & higher & better & better & higher \\
\hline $\begin{array}{l}\text { aluminum } \\
\text { alloy } \\
\text { frame }\end{array}$ & high & good & good & Low \\
\hline $\begin{array}{l}\text { steel } \\
\text { frame. }\end{array}$ & high & good & common & Higher \\
\hline
\end{tabular}

In 2013,the well-known material suppliers DuPont has been launched the solution that based on polymer 
composite materials' e-Frame integration frame bracket, a comprehensive comparison, the cost lower than traditional aluminum alloy frame and support assembly. Europe and the United States have developed solar stent made of plastic material, Taiwan Nami carbon tube company has mastered this technology, multi class model of polymer materials of non-metallic support has been developed in abroad, and been put into the actual production ${ }^{[10]}$.

Classified according to the installation of solar bracket can be divided into: welded and assembled.

TABLE II. COMPARES THE PERFORMANCE OF DIFFERENT INSTALLATION FOR SOLAR MOUNTING

\begin{tabular}{|l|l|l|l|l|}
\hline $\begin{array}{l}\text { Bracket } \\
\text { form }\end{array}$ & $\begin{array}{l}\text { Connecti } \\
\text {-on } \\
\text { strength }\end{array}$ & $\begin{array}{l}\text { Corrosion } \\
\text { resistance }\end{array}$ & $\begin{array}{l}\text { Aestheti } \\
\text { c } \\
\text { level }\end{array}$ & $\begin{array}{l}\text { Construc } \\
\text {-tion } \\
\text { speed }\end{array}$ \\
\hline Welded & Higher & Worse & Worse & Slower \\
\hline $\begin{array}{l}\text { Assembl } \\
\text { ed }\end{array}$ & Higher & Better & Better & Faster \\
\hline
\end{tabular}

II. PHOTOVOLTAIC SOLAR POWER STATION GROUND MOUNTING SYSTEM DESIGN PRINCIPLES AND LOAD ANALYSIS

PV mounting structure design is an important part of Photovoltaic power plant design, and its design principles currently lack the appropriate specifications. According to the other current specifications for guidance and reference to foreign other specifications, Such as Japan's standard "solar array with support design standards (JIS 89552004)" gives the value of wind load requirements, and establishes of a theoretical method to calculate the PV mounting structure ${ }^{[11]}$.

As a hypothetical load for solar array support structure, Including fixed-lasting effects and natural forces of wind pressure load, snow load and seismic load, etc. In addition, there are also have load generated due to temperature change "load temperature", but in addition to the long member is welded a support structure, the load is small compared with the other, and therefore it could be negligible.

a) Fixed load(G): Sum of Component mass(MG) and Supports mass.

b) Wind pressure load(W):Sum of Wind pressure on the component(MW) and Wind pressure on support(KW).

c) Snow load(S): And the component perpendicular to the surface of the snow load.

d) Earthquake load(K): Horizontal earthquake forces on support(In the steel bracket, the important of seismic load generally less than the pressure) ${ }^{[12] .}$

Because PV modules and mounting system with a large area by the wind, light weight and other characteristics, so that the wind load has become a major PV system load to bear. Whether it is time to stand downwind structural strength and deformation demands, or when a headwind on the basis of anti-overturning requirements are a controlling Photovoltaic stent design conditions. Therefore, a reasonable wind load is an important part of Photovoltaic brackets design.
For the ground solar PV mounting systems, it need to ensure that within 25 years the structure must be solid and reliable, able to withstand such as environmental erosion, wind and snow loads and other external loads, safe and reliable installation with minimal installation costs to reach the maximum effect of the use, almost maintenancefree, reliable maintenance, recyclable. At present, some enterprise apply a high abrasion resistant material to resist wind loads, snow loads and other corrosive effect, and utilizes anodized aluminum, thick galvanized steel, stainless steel, anti-aging and UV technology to ensure the ground solar power PV mounting system life ${ }^{[13]}$.

\section{COMPREHENSIVE PERFORMANCE ANALYSIS OF SOLAR PV MOUNTING SYSTEM FOR THE GROUND STATION}

In this paper, according to the optimum tilt angle of fixed, horizontal single-axis tracking, diagonal single axis tracking type and dual axis tracking classification for discussion. For a fixed bracket, due to the latitude and bracket angle are the most important influence for the area covered, so in the same latitude, Fixed angle bracket covers area is the smallest .but because of its inclination is fixed and can not accept the maximum solar radiation, so its solar radiation gain and power generation gain are the lowest than the other forms of the bracket.

For horizontal single-axis tracking, in the case of the same latitude, which covers an area slightly larger than the fixed bracket, but smaller than the diagonal single axis tracking brackets.

For the diagonal single axis tracking brackets, which cover area are larger than fixed and horizontal single-axis, And with the tilt angle, the greater its cover area, due to diagonal single axis tracking brackets real-time tracking of the sun azimuth , so its solar radiation gain and power generation gain compared with Fixed angle bracket and horizontal single axis tracking are high.

For dual-axis tracking, the covers an area is the largest, because it can track the azimuth and elevation angle of the sun, so the solar radiation gain and power generation gain is greatest.

Generally speaking, Tracking bracket can make the photovoltaic power station power generation gain larger. But it covers an area is largest, high cost of operation and maintenance, And at different latitudes, tracking brackets for Power generation gain there are some differences. Considering the above factors, At this stage, brackets fixing bracket and tracking bracket no obvious good or bad, Tracking brackets is not much better than the fixed brackets, In the actual situation should be analyzed for specific projects then to select the optimal brackets program. 2011 peak domestic photovoltaic power plant installed capacity of more than $3 \mathrm{GW}$ in China, of which more than $90 \%$ of PV power plants are based on a fixed bracket, one of the few stations chosen oblique single and single-axis tracking flat bracket, while dual-axis tracking brackets there large-scale demonstration application ${ }^{[15]}$

\section{SUMMARY AND PROSPECT}

1) For the mounting bracket, there is a problem: the low Power generation rates. Solution is to: develop the best angle bracket and adjustable mounting bracket ${ }^{[16]}$. For tracking bracket, a common problem is: complex structure, reliability is lower than the 
2) mounting bracket and own energy consumption, higher costs than the mounting bracket. Solution is to: simplify the structure, improve reliability, reduce their energy consumption, improve power generation rate, the proposed development of the low-angle oblique single-axis tracking system.

3) For the installation of solar PV mounting, installation complexities and time-consuming problem consuming work, the solution is to: develop integrated solar PV mounting bracket or modular solar system.

4) For the production process from the current holder of the extensive structure, simple step by step process to develop precision. For durability and lightweight trend, should the development and application of new composite materials PV.

\section{ACKNOWLEDGMENT}

This work was financially supported by A project Funded by the Priority Academic Program Development of Jiangsu Higher Education Institutions (PAPD); Jiangsu policy guidance class program (Cooperative) Project: Research of PV Mounting System for Solar Power Station and it's key technology (June 2015 has been publicized) and the Nantong University Natural Science Foundation (No.14H118).

\section{REFERENCES}

[1] Zhao Juanni, Huang Fuguo. Solar photovoltaic power generation technology and power system. Science and Technology Vision, 2013(7):145-146.

[2] Yang Jinghuan, cheng Zhonghua. The solar power outlook of the 21st century[J]. Journal of Shanghai University of Electric Power, 2001.17(4):23-28.

[3] Wei Bo, Luo Zhiwen, Ma Xiaojin, et al. Efficiency analysis of overshoot tracking system on solar energy absorb device[J].
Journal of Hebei University of Science and Technology. 2013,34(4):377-380.

[4] JIA Yinxin, Zhang Lei, Jin Ye, et al. Design and research of solar energy heating system[J]. Hebei Journal of Industrial Science and Technology, 2012, 29(6):509-511.

[5] Easan D; Anthony L, Paul D; et al. Relative performance of tracking versus fixed tilt photovoltaic systems in the USA. Progress In Photovoltaics.2014.22(12):1302-1315.

[6] Wang Changgui, Wang Sicheng. Practical solar photovoltaic technology[M]. Beijing: Chemical Industry Press, 2010.

[7] Lin Juan, Xu Rongfeng, Li Ming. Tracking flat panel PV module output performance[J]. Solar Energy. 2010(10):25-28.

[8] GanSU Gneri Solar Power Limited Liability Company. Oblique / flat single-axis tracking solar photovoltaic power generation module device[P]. China : 201020112723.8.2010-10-13.

[9] Gao Dianjun, Zhang Aipin, Ai Fang, et al. Elevation tracking device /support of solar power unit. China : 201210261937.5.2012-7-26.

[10] Abdallah S. The effect of using tracking systems on the voltagecurrent characteristics and power generation of flat plate photovoltics[J].Energy conversion management, 2004,45(1112):1671-1679.

[11] Cheng Yuan. Design of PV mounting structure optimization[J]. Electrotechnical Application. 2013.32(17).76-79.

[12] Yao Yingxue; Hu Yeguang; Gao Shengdong;A multipurpose dualaxis solar tracker with two tracking strategies. Renewable Energy.2014.72:88-98.

[13] Chen Yan, Cao Xiaoning, Lan Yunpeng, et al The analysis of different brackets in large photovoltaic plants[J]. Electrical Engineering, 2013,(8):16-19,23.

[14] Ministry of Industry and Information Technology Research Institute CCID Situation Analysis PV industry group. 2013 China PV Industry Development Prospect. China Electrical Equipment Industry. 2013(02).9-11.

[15] Wang Jianmin, Zhang Xiaowei, Kong Jing. Method for determining on optimum tilt angle of fixed PV array[J]. Renewable Energy Resources,2013,31(2):108-110.

[16] Karimov S, Saqibm P. A simple photovoltaic tracking system[J].Solar Energy Material And Solar Cells,2005,87(14):4959. 